\title{
Música durante a hospitalização para promover saúde: significados de crianças e adolescentes em tratamento oncológico
}

Music during hospitalization to promote health: meanings of children and adolescents undergoing cancer treatment

Música durante la hospitalización para promover la salud: significados de los niños y adolescentes em tratamiento contra el cáncer

Simone dos Santos Pereira Barbosa ORCID: https://orcid.org/0000-0003-2328-4993 Universidade Federal da Fronteira Sul, Brasil E-mail:mone.96@hotmail.com Jeane Barros de Souza ORCID: https://orcid.org/0000-0002-0512-9765 Universidade Federal da Fronteira Sul, Brasil E-mail: jeane.souza@uffs.edu.br

Angélica Zanettini Konrad ORCID: https://orcid.org/0000-0003-1712-9073 Universidade Federal da Fronteira Sul, Brasil E-mail: angélica.zanettini@gmail.com

Tassiana Potrich

ORCID: https://orcid.org/0000-0002-5180-5736 Universidade Federal da Fronteira Sul, Brasil E-mail: tassiana.potrich@uffs.edu.br Maria Sylvia de Souza Vitalle ORCID: https://orcid.org/0000-0001-9405-4250 Universidade Federal de São Paulo, Brasil E-mail: sylviavitalle@gmail.com

Ivonete Teresinha Schulter Buss Heidemann ORCID: https://orcid.org/0000-0001-6216-1633 Universidade Federal de Santa Catarina, Brasil E-mail: ivoneteheideman@gmail.com

Crhis Netto de Brum

ORCID: https://orcid.org/0000-0002-2970-1906 Universidade Federal da Fronteira Sul, Brasil E-mail:crhis.brum@uffs.edu.br

\begin{abstract}
Resumo
Objetivo: compreender os significados do processo de hospitalização e da utilização da música como promotora da saúde, na percepção de crianças e adolescentes em tratamento oncológico. Método: pesquisa exploratória, descritiva, de abordagem qualitativa, fundamentada nos pressupostos da Promoção da Saúde e do Interacionismo Simbólico. Contou com a participação de 11 crianças e adolescentes, entre sete e 13 anos, que vivenciaram a hospitalização devido ao câncer. A coleta de dados ocorreu em 2019 por meio de entrevista semiestruturada. Os dados foram analisados conforme a análise de conteúdo. Resultados: as crianças e os adolescentes significaram a hospitalização como um processo de difícil adaptação que envolve mudança de rotina, anseios e dor. Apontaram que a música auxilia no enfrentamento da hospitalização, promovendo o seu bem-estar por apresentar aproximação do lar, da família, por trazer os sentimentos de alegria e felicidade. Conclusão: a música traz significados no processo de hospitalização de crianças e adolescentes em tratamento oncológico, sendo uma tecnologia de cuidado para promover saúde.
\end{abstract}

Palavras-chave: Criança; Adolescente; Câncer; Promoção da saúde; Música.

\section{Abstract}

Objective: to understand the meanings of the hospitalization process and the use of music as a health promoter, in the perception of children and adolescents undergoing cancer treatment. Method: exploratory, descriptive research, with a qualitative approach, based on the assumptions of Health Promotion and Symbolic Interactionism. It counted on the participation of 11 children and adolescents, between seven and 13 years old, who were experiencing hospitalization due to cancer. Data collection took place in 2019 through semi-structured interviews. The data were analyzed 
according to the content analysis. Results: children and adolescents meant hospitalization as a process of difficult adaptation that involves a change in routine, anxieties and pain. They pointed out that music helps in coping with hospitalization, promoting their well-being by presenting an approach to home, family, by bringing feelings of joy and happiness. Conclusion: music brings meaning to the hospitalization process of children and adolescents undergoing cancer treatment, being a care technology to promote health.

Keywords: Child; Adolescent; Cancer; Health promotion; Music.

\section{Resumen}

Objetivo: comprender los significados del proceso de hospitalización y el uso de la música como promotora de salud, en la percepción de niños y adolescentes en tratamiento oncológico. Método: investigación exploratoria, descriptiva, con enfoque cualitativo, basada en los supuestos de Promoción de la Salud e Interaccionismo Simbólico. Contó con la participación de 11 niños y adolescentes, de entre siete y 13 años, que estaban siendo hospitalizados por cáncer. La recolección de datos se realizó en 2019 a través de entrevistas semiestructuradas. Los datos se analizaron según el análisis de contenido. Resultados: los niños y adolescentes entendieron la hospitalización como un proceso de difícil adaptación que implica un cambio de rutina, ansiedades y dolor. Señalaron que la música ayuda a sobrellevar la hospitalización, promoviendo su bienestar al presentar un acercamiento al hogar, a la familia, al traer sentimientos de alegría y felicidad. Conclusión: la música aporta significados al proceso de hospitalización de niños y adolescentes en tratamiento oncológico, siendo una tecnología asistencial para promover la salud.

Palabras clave: Niño; Adolescente; Cáncer; Promoción de la salud; Música.

\section{Introdução}

O ser criança apresenta características ímpares, envolvendo o crescimento biológico, o desenvolvimento cognitivo, as descobertas, o apoio familiar conforme as relações saudáveis da idade e a presença do ato de brincar. De tal maneira, encontrase a particularidade do ciclo de vida da adolescência, período de transição do infantil para o início das responsabilidades do mundo adulto, fase também em que se encontra maior inserção no meio social, como a criação dos grupos sociais (Sousa, 2019).

Quando ocorre um acometimento na saúde da criança ou do adolescente, há uma reação diferenciada, surgindo sentimentos, sensações e mudanças, principalmente na vivência de uma doença oncológica. O câncer infantojuvenil abrange a idade de zero a 19 anos, tendo maior incidência no território brasileiro os casos que envolvem o sistema sanguíneo como leucemias, seguido do sistema linfático (INCA, 2016).

Para o ano de 2020 foram estimados um total de 8.460 novos casos no Brasil, sendo 4.150 do sexo feminino e 4.310 do sexo masculino (INCA, 2020). O câncer tem sido a principal causa de mortalidade desta população no Brasil, mas com a evolução do conhecimento, tem-se alcançado o tratamento e manutenção da qualidade de vida (INCA, 2020). No âmbito do câncer infantojuvenil, muitas crianças e adolescentes são hospitalizados com vistas a realizar avaliação, diagnóstico e acompanhamento em quimioterapia, radioterapia e cirurgia. No delongar desse processo, vivenciam sentimentos como medo, angústia, sensação de abandono, mudança no núcleo familiar, identidade visual alterada e conflito psicológico (Pontes, et al., 2018).

O processo de hospitalização é configurado como um momento de fragilidade do indivíduo, envolvendo algumas transformações no cotidiano de cada ser (Araújo, 2018). Dentre estas modificações, destaca-se o distanciamento do núcleo familiar, das rotinas e o aparecimento de diversos sentimentos como: saudade dos familiares e amigos, medo por estar em um local diferente, ansiedade em cada procedimento, lembrança da perda ou adoecimento de um ente querido e anulação da identidade, por sentir-se dependente de outras pessoas (Florisbal \& Donelli, 2017).

No processo de hospitalização sobrepuja a singularidade ao tratar-se de crianças e adolescentes (Gomes, Fernandes \& Nóbrega, 2016; Sousa, 2019). A internação para estes públicos é vista como um estágio que provoca sentimento de estresse pelo ambiente desconhecido. Soma-se a insegurança gerada pelos procedimentos invasivos, o desconhecimento dos profissionais e o afastamento dos familiares, rotinas e círculo de amigos (Azevedo, Júnior \& Crepaldi, 2017; Reis et al., 2018), muito importante para o seu sentido de pertencimento e desenvolvimento de habilidades sociais. 
Diante do exposto, torna-se fundamental que a equipe de saúde compreenda e utilize meios que possam facilitar o processo de hospitalização da criança e do adolescente em tratamento oncológico, buscando promover a saúde no ambiente hospitalar. Ressalta-se que a promoção da saúde, conforme descrito na Carta de Ottawa de 1986, resulta em ações que oportunizam que os indivíduos façam escolhas mais favoráveis ao seu bem-estar, em busca de melhoria da qualidade de vida (Malta et al., 2018). Também expõe estratégias para o ato de promover saúde, como a criação de ambientes favoráveis (WHO, 1986).

No Brasil, em 2006, foi instituída a Política Nacional de Promoção da Saúde (PNPS), a qual estabelece diretrizes e estratégias para promover a saúde da população, englobando princípios e valores como a humanização, integralidade e felicidade dos indivíduos e comunidades (BRASIL, 2017). Essas podem ser inseridas pela utilização de rodas de conversas, pela ludicidade e inserção do brinquedo terapêutico, do uso de jogos, pinturas, como também a figura do palhaço (Oliveira et al., 2018; Rodrigues et al., 2019). Dentre as possibilidades para promover a saúde no ambiente hospitalar destaca-se a utilização da música, que proporciona o bem-estar, qualidade de vida, desenvolvimento cognitivo, expressão de sentimentos e humanização (Rodrigues, 2019).

A música promove vários benefícios no processo de hospitalização, tais como: redução ou esquecimento da sensação de dor, entretenimento, desenvolve a criatividade, alegria, afastando pensamentos de perda e abandono do familiar (Silva \& Piovesan, 2018; Souza et al., 2020). Assim, a música desvela-se como um recurso terapêutico e uma tecnologia de cuidado para o profissional enfermeiro na assistência à saúde das crianças e adolescentes em tratamento oncológico. Inclusive, o Sistema Único de Saúde (SUS) oferece, de forma integral e gratuita, 29 procedimentos de Práticas Integrativas e Complementares (PICS) à população brasileira, que inclui a música como prática de cuidado (Ferreira, Cunha, Mene ghim \& Checchi, 2020). No entanto, ainda há escassez de estudos que apontam evidências científicas sobre a utilização da música no ambiente hospitalar para promover a saúde, sendo mais voltados para o tratamento e recuperação, o que justifica a importância desta pesquisa.

A partir de então, emergiu a pergunta de pesquisa: quais os significados do processo de hospitalização e da utilização da música como promotora da saúde, na percepção de crianças e adolescentes em tratamento oncológico? Logo, este estudo objetivou compreender os significados do processo de hospitalização e da utilização da música como promotora da saúde, na percepção de crianças e adolescentes em tratamento oncológico.

\section{Metodologia}

Trata-se de uma pesquisa do tipo exploratória, descritiva, de abordagem qualitativa, fundamentada nos pressupostos teóricos da Promoção da Saúde e do Interacionismo Simbólico. A pesquisa qualitativa se entrelaça ao Interacionismo Simbólico, pois busca compreender e trazer os significados do fenômeno estudado, repercutindo apontamentos das vivências e olhar individual perante cada ação e momento (Patias \& Hohendorff, 2019). O Interacionismo Simbólico relaciona os significados de ações, interações, meios como se comunica um determinado grupo e como assim é compreendido (Correa, 2017). Foi descrito primeiramente por George Herbert Mead e surgiu como método em 1937 por meio da análise de Herbert Blumer, o qual desenvolveu a interpretação sistêmica da interação (Haguette, 2013).

Cabe salientar que esta pesquisa se desenvolveu em um hospital infantil do município do oeste catarinense, o qual é referência na atenção à saúde de crianças e adolescentes da região, como o atendimento e linha de cuidado em oncologia. O estudo se originou a partir das ações de um programa de extensão do curso de Enfermagem de uma universidade pública do Sul do Brasil, que tem por objetivo promover a saúde de crianças, adolescentes, seus familiares e profissionais que atuam no ambiente hospitalar, tendo a música como tecnologia de cuidado. O programa promove momentos musicais na instituição hospitalar, nos quartos e corredores da unidade oncológica pediátrica, onde docentes e discentes de enfermagem cantam 
músicas contendo melodias e letras apropriadas para cada situação, fazendo uso de dois violões e um violino, com duração de aproximadamente cinco minutos em cada local. Para as crianças, utilizam também instrumentos de percussão, fantoches e bolhas de sabão para melhor interação com o público infantil. Ressalta-se que o grupo adentra os quartos para realizar o momento musical somente após a devida autorização dos familiares e das crianças e adolescentes.

Este estudo contou com a participação de seis crianças e cinco adolescentes, sendo seis do sexo feminino e cinco do sexo masculino, que estavam internados na unidade de oncologia de um hospital público pediátrico de Santa Catarina, Brasil. Outras duas crianças foram convidadas a integrar o estudo, mas não aceitaram participar. Como critérios de inclusão considerou-se aqueles hospitalizados na unidade oncológica com idade entre seis e 17 anos, em condições cognitivas e físicas para participar da pesquisa. Considerou-se critério de exclusão os que não tinham recebido momentos musicais do programa de extensão durante a sua hospitalização.

A produção de dados ocorreu no período de outubro a dezembro de 2019, após a realização do momento musical. As informações foram coletadas por meio de entrevista com roteiro semiestruturado, envolvendo questões sobre a compreensão de saúde, rotinas fora do hospital, vivência do processo de hospitalização, possibilidades de promover saúde no ambiente hospitalar e os significados/sensações que a música proporciona durante a internação. As entrevistas foram conduzidas pela equipe do programa de extensão, também autores deste estudo.

As entrevistas foram realizadas de maneira individual, no quarto das crianças e adolescentes, sem a presença de seus responsáveis, com a utilização de uma linguagem apropriada para cada público, com duração aproximada de meia hora. As entrevistas foram gravadas com o apoio de um smartphone e transcritas na íntegra.

Os dados foram organizados e analisados de acordo com a análise de conteúdo na modalidade temática, descrita por Minayo (2014). Tal análise conta com a frequência do aparecimento dos objetivos do estudo, que traz consigo um significado dos depoimentos, apresentando três fases: 1) pré análise: realizou-se a leitura flutuante dos dados obtidos no material coletado, buscando aproximar do objetivo inicial, hipóteses com elementos encontrados na coleta; 2) codificação de dados: elencou-se a escrita de pequenos trechos, palavras, frases dos elementos coletados, a qual aproximaram da significância da pesquisa; 3 ) categorização ou subcategorização: classificação, interpretação do material e aproximação das categorias teóricas, alcance do objetivo da pesquisa (Minayo, 2014). A partir de então, emergiram três categorias, que serão em seguida apresentadas e discutidas.

Quanto aos aspectos éticos, ressalta-se que antes da realização das entrevistas, primeiramente foi apresentado os objetivos do estudo para os pais e/ou responsáveis das crianças e/ou adolescentes. Em seguida, as crianças e os adolescentes assinaram o Termo de Assentimento e seus responsáveis o Termo de Consentimento Livre e Esclarecido (TCLE). Para garantir o anonimato dos participantes, decidiu-se denominá-los por personagens de animação infantil, que foram escolhidos conforme os objetos que continham em seus quartos e/ou nos depoimentos que retratavam acerca de algum personagem favorito, surgindo: Violeta Pêra, Elza, Moana, Minnie, Ben 10, Pedrita, Pequena Sereia, Simba, Timão, Jimmy Neutron e Homem Aranha. A pesquisa obteve aprovação do Comitê de Ética em Pesquisa com Seres Humanos (CEP), aprovado com o parecer número 3.324.427 e protocolo CAAE 11511319.1.0000.5564.

\section{Resultados e Discussão}

O estudo envolveu 11 participantes, sendo seis do sexo feminino e cinco do sexo masculino. Entre eles, dois tinham seis anos, um de sete anos, um de oito anos, dois de nove anos, um de dez anos, um de 11 anos, um de 12 anos e dois de 13 anos. O período de hospitalização variou de um a 12 dias. Quanto ao diagnóstico de câncer, nem todos os participantes do estudo tinham ciência do seu real estado: cinco sabiam do seu diagnóstico e consequentemente o motivo da sua hospitalização 
e seis não tinham conhecimento sobre a existência do câncer, relacionando a internação com a necessidade de realizar exames e diminuir a dor em determinada região do corpo.

$\mathrm{Na}$ análise dos dados, emergiram três categorias: 1) Vivência do processo de hospitalização: significados aos olhos das crianças e adolescentes; 2) Simbologia de saúde e promoção da saúde; 3) Música como promotora da saúde no hospital: desvelando significados.

\section{Vivência do processo de hospitalização: significados aos olhos das crianças e adolescentes}

O processo de hospitalização apresenta características ímpares para aqueles que estão vivenciando esse momento. Para crianças e adolescentes, retrata um episódio de grandes mudanças, pois estão longe da realidade que costumam viver, deixando de realizar atividades que gostam, como as descritas a seguir:

"Eu gosto de brincar, de treinar o violão, de tocar minha bateria, de ir na igreja tocar o pandeiro, e brincar com a minha irmã." (Ben 10).

“Gosto de treinar futebol [...]” (Simba).

“[...] Eu gosto de pintar, costurar, fazer tema [...] Se tiver tecido e linha, eu costuro" (Minnie).

"Eu gosto de jogar bola, brincar de bicicleta, eu gosto de brincar de pega pega, de esconde esconde, de pique esconde [...]" (Jimmy Neutron).

No processo de hospitalização ocorrem mudanças que são intrínsecas na rotina das crianças e adolescentes, tais como: a distância do meio familiar, das brincadeiras que auxiliam no desenvolvimento, do contato com amigos, da identificação da personalidade no caso dos adolescentes (Sousa, 2019; Oliveira et al., 2018; Freitas \& Agostini, 2019). O processo de hospitalização apresenta para eles um significado, uma realidade das relações propostas no momento, em que cada criança ou adolescente simboliza, conforme a teoria do Interacionismo Simbólico, em que as relações e suas ações resultam em um significado para um indivíduo ou comunidade (Gabatz, Schwartz \& Milbrath, 2016).

O processo de hospitalização apresenta-se como um momento de sentir falta das brincadeiras, comum na vivência das crianças (Barbosa \& Crahim, 2019). O fato é que por estar em um local que não permite a continuidade das brincadeiras, da mesma alimentação realizada em casa e da proximidade da família, pode retratar um significado desagradável e impactar sua visão de mundo e relação com a equipe de saúde e, em consequência, o enfrentamento da internação e do tratamento:

"[...] Chato [...] eu prefiro ficar em casa, porque em casa eu como melhor. Aqui eu não como muito e em casa eu consigo comer de tudo. Aqui é diferente, essa comida eu não gosto” (Minnie).

“[...] é bastante ruim [...] aqui não tem comida muito boa [risos]” (Jimmy Neutron).

"Eu sinto mais falta é de ficar com meus irmãos [...] de ficar em casa, comer comida do meu pai” (Elza).

"Sinto falta de brincar de boneca" (Pedrita).

Desvela-se como um fator negativo o significado do processo de hospitalização, considerando que além de sair de sua vida normal, somam-se os procedimentos diários, que causam estranheza (Barbosa \& Crahim, 2019). Para as crianças e adolescentes, o hospital é considerado um espaço fechado, com escassas atrações, de difícil ambientalização. Os procedimentos que ocorrem no hospital repercutem em medo, insegurança, saudade e a sensação de desconforto (Reis et al., 2018), como enjoo, dor e necessidade de ficar em repouso: 
"Eu não saio daqui de dentro" (Ben 10).

"[...] é trancado [...]. Eles me tratam bem, eu como bem, mas não tem nada pra fazer" (Simba).

“Eu sinto muito enjoo" (Timão).

"Muito ruim ficar com esse soro na mão e ficar deitado [...] Dói minha barriga" (Jimmy Neutron).

"Eu sinto saudade da minha mãe e da minha irmã "(Moana).

O hospital é visto pelas crianças e adolescentes, como um local frio, que gera diversos sentimentos e sensações como o medo e a saudade. Significados estes que se originaram durante as relações anteriores com o espaço hospitalar, ou mesmo pela visão expressa pelos familiares e relações da sociedade em que estão envolvidos.

Os participantes do estudo referiram o desejo de retornar para casa e para as suas rotinas. A sinalização de sentir o desejo de melhorar, é relembrado pelas relações que os indivíduos sentem fora do ambiente hospitalar por meio de lembranças com o meio em que vive: família, comunidade e sociedade (Gabatz, Schwartz \& Milbrath, 2016):

"Eu gosto mais é de ficar bom [...] ficar bem dos remédios e da dor de barriga [...]” (Jimmy Neutron).

“Eu sinto falta das minhas irmãs, da minha mãe, do meu pai e dos meus tios [...]” (Ben 10).

“[...] sinto falta da escola, da minha família, e dos meus treinos de futebol” (Simba).

Vale destacar que a condução da equipe de saúde durante o processo de hospitalização de crianças e adolescentes no setor da oncologia é fundamental para que estes se sintam mais aconchegados e confiantes, podendo enfrentar este momento de maneira mais tranquila, compreensiva, com resiliência e portanto, de forma cooperativa para que se sintam mais confortáveis, o que pode ter implicações importantes em tempo de internação e maior segurança para aderir ao tratamento instituído, por exemplo. Assim, a visão positiva pode estar relacionada à acolhida da equipe, a competência dos profissionais da saúde frente à assistência prestada, como agir conforme observação da realidade necessária para aquele indivíduo (Florisbal \& Donelli, 2017). Nesse aspecto, alguns participantes significaram a hospitalização como um momento positivo:

“[...] é legal [...]. Eu tenho que fazer exercício [...] estou fazendo para as minhas pernas, que estou internada porque estou com diabetes" (Elza).

"É bom, eles tratam bem a gente" (Violeta Pêra).

Por meio da percepção das crianças e adolescentes, compreende-se que a maneira como os profissionais conduzem sua assistência, pode-se facilitar o processo de hospitalização, dado que apontam a hospitalização como um período de difícil adaptação, mudança da rotina, distância de familiares e amigos, ambiente fechado. Assim ferramentas que proporcionam acolhimento têm como base as ações promotoras de saúde, podendo se apropriar de instrumentos lúdicos, os quais possibilitam a simbologia de aproximação de crianças e adolescentes com o espaço hospitalar.

\section{Simbologia de saúde e promoção da saúde}

A compreensão da saúde é vista como um significado individual, mas que é construído coletivamente, sendo gerado nas relações que existem em uma família e sociedade (WHO, 1986). Nesse aspecto, o Interacionismo Simbólico reforça a importância dos significados, sendo crucial que os profissionais da saúde possam compreender a simbologia de saúde para os indivíduos, considerando que prestam a assistência e visam uma melhoria do cuidado a ser prestado (Utzumi et al., 2018).

Para as crianças e adolescentes, a saúde é uma simbologia direcionada ao modelo hospitalocêntrico, direcionada à 
saúde física e ausência de doença (Pettres \& Da Ros, 2018). Os participantes do estudo significaram saúde como a identificação do corpo, sem nenhuma alteração ou problema:

"Quando nós não temos saúde, a gente fica doente [...] é se nós tivermos saúde, ela ajuda nosso corpo a viver melhor, a gente não precisa ficar tomando remédio” (Violeta Pêra).

“[...] é uma pessoa que não tem doença, que não tem problemas [...]” (Simba).

"É ter uma saúde boa, não ficar doente, ficar saudável” (Minnie).

Algumas crianças e adolescentes hospitalizados significaram a saúde como um bom condicionamento físico. Mas ampliaram o olhar, ao considerar o equilíbrio de uma alimentação saudável e a importância da prática da atividade física, a identificação do ato de estar feliz, visto felicidade como saúde, conforme também descrito na PNPS (Brasil, 2017; Pettres \& Da Ros, 2018). Assim, trouxeram a significância atribuída à saúde conforme o contexto do meio que estão inseridos, na comunidade e família, comum ao entender-se que a simbologia de determinado assunto está vinculada ao meio de inserção e coletivo, conforme aponta o Interacionismo Simbólico (Correa, 2017):

"Saúde é ficar bem, comer bastante salada, sempre fazer exercício, não comer muito doce e nem muito salgado" (Elza).

“[...] é estar sempre bem [...] ah, eu ando de bicicleta, jogo futebol [...]” (Simba).

"[...] é ficar saudável, é se sentir feliz, é ter tudo em ordem no corpo” (Minnie).

Também trouxeram a simbologia, conforme o conceito ampliado de saúde, que se caracteriza pelo completo bemestar, envolvendo o biopsicossocial, a espiritualidade, a e a oferta de assistência em serviços de saúde de maneira integral (Bezerra \& Sorpreso, 2016), necessitando manter equilíbrio do sono, da relação familiar e buscar estratégias para o controle emocional:

“[...] quando eu durmo, eu consigo mesmo descansar [...]” (Ben 10).

“O remédio, é a minha mãe [...] Ela me dá abraço e me dá uns beijos para eu não sentir dor [...]” (Jimmy Neutron).

“Para mim viver é ter saúde e Deus” (Violeta Pêra).

“[...] o que eu faço para ficar bem quando eu estou estressado é ficar com fone escutando música” (Simba).

Para promover a saúde no âmbito hospitalar, faz-se necessário compreender que é o meio que dá sequência na capacidade individual e coletiva sobre como praticar a melhor forma para obter-se qualidade de vida e bem-estar, com vistas a gerar autonomia e empoderamento do indivíduo sobre esse processo (Brasil, 2017; WHO, 1986). Nesse contexto, os participantes do estudo referiram algumas possibilidades para promover a saúde durante o processo de hospitalização:

\footnotetext{
“Ah, aqui eu tenho a brinquedoteca [...]” (Violeta Pera).

“[...] tem brinquedo, tem as pessoas ajudando [...]” (Elza).

“[...] eles (profissionais) tratam muito bem a gente, eles brincam com a gente [...]” (Violeta Pêra).

"Eu fiz um desenho com tintas e penduraram na parede [...]" (Moana).
} 
Entende-se que as práticas levantadas como promotoras da saúde pelas crianças e adolescentes em tratamento oncológico estão relacionadas ao sentirem-se bem, com destaque para a ludicidade no ato de brincar e desenhar. A simbologia voltada para as atividades lúdicas demonstra sua relevância e significado na vivência do processo de hospitalização, pois é um mecanismo de aproximação com os profissionais que prestam a assistência, além de amenizar as mudanças e procedimentos da internação, gerando diversão, felicidade e criatividade (Barbosa \& Crahim, 2019 \& Gabatz, Schwartz \& Milbrath, 2016).

Além das práticas lúdicas, vinculadas ao brincar e desenhar, os participantes citaram a alimentação e a atividade física, em que descreveram o caminhar no corredor, como uma outra possibilidade para promover a sua saúde durante a hospitalização. A alimentação e a atividade física são descritas na Carta de Ottawa como requisitos para se obter saúde (WHO, 1986):

“A alimentação ajuda [...] o pessoal da cozinha ajuda e vem suco, às vezes café [...]” (Ben 10).

"O que me faz bem é quando eu ando no corredor." (Simba).

"Eu caminho um pouco lá fora porque os médicos dizem se eu mexer bastante, eu vou ter mais energia, e posso ir para casa mais cedo." (Jimmy Neutron).

Dentre as ações destacadas para promover a saúde no hospital mencionaram também a importância dos profissionais que atuam no local, que os auxiliam no seu bem-estar:

"Porque eles ajudam tudo [...] Na hora que a enfermeira veio me ajudar para tomar banho, que aí melhorou (Homem Aranha).

“[...] tem os médicos, as enfermeiras, todo mundo está ajudando.” (Elza).

"Quem tem câncer, eles colocam na quimioterapia, para passar. Eles dão remédio, eles dão soro, tipo eu to em jejum, ai por exemplo, eu vou ficar em jejum aí eles dão soro, para mim não ficar com fome e sede" (Minnie).

A união, a escuta, o acolhimento, a comunicação e o trabalho em equipe são pontos essenciais destacados na Política Nacional de Promoção da Saúde (PNPS) para atuação nos serviços de saúde (BRASIL, 2017). Nesse contexto, conforme o Interacionismo Simbólico, entende-se que as ações de aproximação dos profissionais com as crianças e adolescentes hospitalizados, possibilita a criação de uma relação de confiança, carinho e respeito referente ao deixar-se ser cuidado e ressignifica esse cuidado, o qual assemelha-se à relação com a comunidade, família e ao ambiente familiar (Gabatz, Schwartz \& Milbrath, 2016; Correa, 2017; Utzumi, et al., 2018).

No entanto, despontaram depoimentos que desvelaram que no hospital não existem ações de promoção da saúde, relacionando com o desejo de retornar para casa:

"Não tem nada aqui e eles não me liberaram para ir para casa, ligeiro" (Jimmy Neutron).

“Não tem nada [...]” (Moana).

São difíceis os processos de adaptação quando se trata da hospitalização de crianças e adolescentes. Mas podem-se desenvolver ações para que se torne mais agradável essa vivência, como a utilização da música no hospital:

“Aqui tem música [...]” (Elza). 
A música pode ser uma maneira de promover saúde de maneira lúdica, que aproxima crianças e adolescentes, o que oportuniza bem-estar, brincar, felicidade, além de ser uma aliada no cuidado prestado pelos profissionais (Silva \& Piovesan, 2018). Deste modo, percebe-se que a música gera sensações e significados para crianças e adolescentes que vivem com uma doença oncológica e que estão vivenciando o processo de hospitalização, como será abordado a seguir.

\section{Música como promotora da saúde no hospital: desvelando significados}

A música é uma ferramenta que pode ser utilizada para promover saúde em diversos cenários, inclusive nos diferentes espaços dos setores da saúde, envolvendo o ambiente hospitalar. A música se destaca por proporcionar bem-estar físico e mental, como também promove práticas sociais, além de ser uma maneira de assistência no cuidado dos profissionais da saúde, em destaque o profissional enfermeiro (Cardoso et al., 2016). As crianças e adolescentes desvelaram que a música repercute em felicidade e animação para a unidade oncológica:

\section{"[...] a música trouxe felicidade para as crianças" (Violeta Pêra). \\ "A música deixa a pessoa animada [...] feliz, pra ela esquecer que ela está no hospital” (Simba). \\ “Alegria” (Pedrita).}

Os participantes do estudo significaram que a música proporciona alegria, trazendo o esquecimento da tristeza e da lembrança de estar dentro de um hospital, sendo que pode simbolizar fonte de apoio na redução da dor, do estresse e da ansiedade causados pelo processo da hospitalização (Silva, Baran \& Mercês, 2016). A manifestação da sensação de felicidade por meio da música evidencia o desenvolvimento do bem-estar, sensação presente no resultado obtido após uma ação de promoção da saúde, conforme apontado na PNPS (Souza et al., 2020; BRASIL, 2017). Portanto, a música pode transformar a maneira de pensar e enfrentar os sentimentos e a dor, trazendo incentivo, confiança e redução da tristeza, possibilitando assim, também, mais uma vez, a promoção de saúde:

"Porque a música tira a cabeça de coisa ruim, o que está sentindo, alguém que já morreu, ou uma dor" (Simba).

"[...] traz alegria, porque as vezes tem crianças que ficam tristes" (Moana).

"A música incentiva as pessoas a se levantarem, se erguer e pensarem melhor" (Violeta Pêra).

"É bem legal e dá mais confiança [...] Mais confiante de eu ir para casa”" (Jimmy Neutron).

No olhar do Interacionismo Simbólico, a relação apontada entre a música e o bem-estar está interligado com a visão que construíram junto a sua comunidade e família, de que a música, o som e a letra proporcionam melhoria em seu estado (Gabatz, Schwartz \& Milbrath, 2016; Correa, 2017). Evidencia-se que a escolha do repertório musical deve ser condizente com a situação que cada ser está vivenciando durante a hospitalização. Nesse aspecto, torna-se relevante observar a idade e as características de cada indivíduo, bem como o ritmo e a letra das músicas para que os seus benefícios sejam evidenciados (Silva, Baran \& Mercês, 2016):

"A letra da música. depende da batida também. Tem pessoas que gostam de ouvir música para se sentir bem [...]" (Minnie).

"Eu senti que a música era boa [...]” (Ben 10). 
Foi apontado que a música também desperta saudades e lembranças da rotina fora do hospital, como a participação na igreja, o ambiente familiar e as festas:

"E eu também lembrei da minha igreja, que lá eles cantavam música animada" (Violeta Pêra).

"Ela também me lembra muito a minha família" (Elza).

"Eu senti saudades do meu irmão, do meu pai e da minha vovó [...]” (Elza).

"Saudades da minha familia [...] Brincar com o mano" (Homem Aranha).

"Saudade do bolo das festas [....]" (Homem Aranha).

A música gera sensação de bem-estar, aproxima as pessoas de sua realidade, do que faz bem quando se pensa em sua singularidade. A música desenvolve a fé e a esperança como maneira de fortalecer o período de hospitalização, lembrando que a espiritualidade também deve estar envolvida no cuidado da saúde (Souza et al., 2019). Ao receberem a música durante a hospitalização, as crianças e os adolescentes significaram como um momento de carinho e de amor, tendo a oportunidade de pensar em Deus:

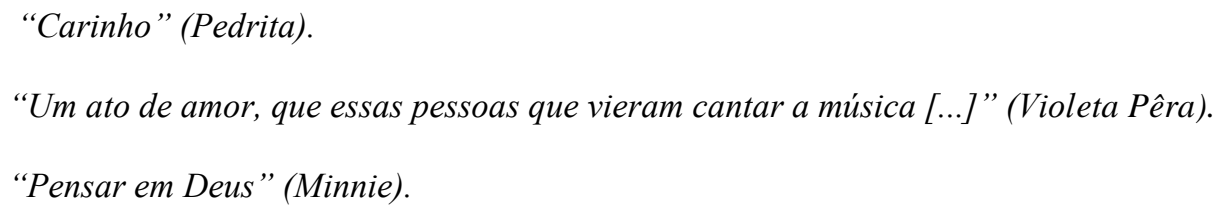

Também compartilharam que a música proporciona a sensação de calma e emoção, com reflexões sobre o momento que estão vivendo:

“A música para mim, ela acalma [...]” (Violeta Pêra).

"Dá vontade de chorar [...] É que quando eu fui colocar o PIC, depois que eu acordei eu tinha sonhado que minha mãe morreu [...] ai quando toca uma música assim, alegre demais, eu fico triste” (Minnie).

$$
\text { “[...] emoção” (Timão). }
$$

A utilização da música como meio de cuidado promove momentos de reflexão e transmite calma para um período que, por vezes, não está sendo de fácil compreensão e adaptação, instigando o crescimento e a criatividade (Silva \& Piovesan, 2018; Silva, Baran, \& Mercês, 2016; Cardoso et al., 2016). Nessa mesma direção, destacaram a simbologia que a música auxilia no desenvolvimento infantil em sua totalidade, como o psicológico, melhor desempenho e confiança:

\footnotetext{
"Porque a música faz com que a gente tenha um desempenho melhor para a saúde"(Jimmy Neutron).

"Porque ela faz a gente crescer e ter mais confiança" (Jimmy Neutron).
}

Ficou evidente que as crianças e os adolescentes em tratamento oncológico significam que a música auxilia na promoção da saúde durante a vivência da hospitalização, tornando-se uma estratégia profícua para ser colocada em prática na assistência a esse público. 


\section{Considerações Finais}

A vivência do câncer na infância e na adolescência repercute em alguns enfrentamentos, como a experiência da hospitalização. Os participantes do estudo significaram essa experiência como um processo de difícil adaptação na oncologia pediátrica, como o afastamento do ambiente familiar e das rotinas diárias, tendo ainda que defrontar-se com procedimentos hospitalares, rodeados por pessoas desconhecidas.

Para as crianças e adolescentes a saúde simboliza bem-estar físico, mas também se desvelou-se o olhar ampliado com a inclusão dos fatores psicológico, social, espiritual, proximidade familiar, carinho, respeito e felicidade. Consideraram que a alimentação, as atividades físicas, o apoio familiar, a maneira de a equipe assistir, o brincar, o desenhar e a música são ações que favorecem a promoção da saúde no ambiente hospitalar.

Neste sentido, a música pode significar uma possibilidade de promover a saúde no ambiente hospitalar, proporcionando bem-estar, redução da dor, socialização, aproximação com a espiritualidade, podendo esta ser considerada uma tecnologia de cuidado para atuação da Enfermagem e demais profissionais da área da saúde na oncologia pediátrica.

Este estudo contribui na ampliação de reflexões sobre os significados da hospitalização para as crianças e adolescentes que vivenciam o câncer, trazendo a música como potencial instrumento para a promoção da saúde e consequente bem-estar, no ambiente hospitalar. Como fator limitante do estudo, cita-se a dificuldade de encontrar ações de intervenção musical dentro da assistência hospitalar, pois exige-se um preparo específico dos profissionais para desenvolver tal atividade. Sugere-se a continuidade de investigação de ações que são concretizadas pelo emprego da música como instrumento de promoção da saúde no espaço hospitalar, a fim de obter maiores evidências científicas.

\section{Referências}

Araújo, L. J. V. F. R. (2018). Ludoterapia: Uma Estratégia De Humanização Da Enfermagem No Cuidado De Pessoas Hospitalizadas. UNIC. https://repositorio.pgsskroton.com/bitstream/123456789/20262/1/LYNDA\%20JULLYANA\%20VICTORIA\%20DE\%20FATIMA\%20RAMOS\%20ARAUJO. pdf

Azevêdo, A. V. S., Júnior, A. C., \& Crepaldi, M. A. (2017). Interação equipe de enfermagem, família, e criança hospitalizada: revisão integrativa. Ciência \& Saúde Coletiva, 22 (11), 3653-3666. https://doi.org/10.1590/1413-812320172211.26362015. 10.1590/1413-812320172211.26362015

Barbosa, G. A., \& Crahim, S. C. F. (2019). A importância do Lúdico no Contexto da Hospitalização. Revista Mosaico, 10 (supl 2 ), 26-31. http://editora.universidadedevassouras.edu.br/index.php/RM/article/view/1779. DOI 10.21727/rm.v10i2Sup.1779

Bezerra, I. M. P., \& Sorpreso, I. C. E. (2016). Concepts and movements in health promotion to guide educational practices. Journal of Human Growth and Development, 26(1), 11-20. https://www.revistas.usp.br/jhgd/article/view/113709/112279. http://dx.doi.org/10.7322/jhgd.113709

Brasil. Ministério da Saúde. (2017). Política Nacional de Promoção da Saúde: PNPS: Anexo I da Portaria de Consolidação ${ }^{\circ} 2$, de 28 de setembro de 2017 , que consolida as normas sobre as políticas nacionais de saúde do SUS/ Ministério da Saúde. Brasília-DF, 2017. http://bvsms.saude.gov.br/bvs/publicacoes/politica_nacional_promocao_saude.pdf

Cardoso, A. V. M., Souza, A. A. M., Silva, P. L. N., Carvalho H. L. A., Alves, E. D., \& Filho, W. A. (2016). Cuidando com arte: a promoção da saúde por meio da música. Revista da Universidade Vale do Rio Verde, 14(1), 714-735. https://dialnet.unirioja.es/servlet/articulo?codigo=5511275.

Correa, A. S. (2017). Interacionismo simbólico: raízes, críticas e perspectivas atuais. Revista Brasileira de História \& Ciências Sociais, 9(17), 176-200. https://dialnet.unirioja.es/servlet/articulo?codigo $=6737540$.

Ferreira, S. K. S., Cunha, I. P., Meneghim, M. C., \& Checchi M. H. R. (2020). Política Nacional de Práticas Integrativas e Complementares no Sistema Único de Saúde. Revista Faipe, 10(1), 21-39. https://revistafaipe.com.br/index.php/RFAIPE/article/view/144/134.

Freitas, T. B., \&Agostini, O. S. (2019). Impactos da hospitalização parcial recorrente sob a perspectiva de crianças e adolescentes com mucopolissacaridoses em um hospital pediátrico. Cadernos Brasileiros de Terapia Ocupacional, 27(3), 564-573. https://www.scielo.br/j/cadbto/a/J4YtvDhXd3Nv66GyzVmNkZb/?lang=pt. https://doi.org/10.4322/2526-8910.ctoAO1636

Florisbal, G. S., \& Donelli, T. M. S. (2017). Revivendo perdas: um estudo com pacientes hospitalizados em uma unidade de internação. Revista da SBPH, 20(1), 75-98. http://pepsic.bvsalud.org/scielo.php?script=sci_arttext\&pid=S1516-08582017000100006.

Gabatz, R., Schwartz, E., \& Milbrath, V. (2016). O interacionismo simbólico no estudo da interação da criança institucionalizada com seu cuidador. CIAIQ2016, 2 (1). https://proceedings.ciaiq.org/index.php/ciaiq2016/article/view/773.

Gomes, G. L. L., Fernandes, M. G. M., \& Nóbrega, M. M. L. (2016). Ansiedade da hospitalização em crianças: análise conceitual. Revista Brasileira de Enfermagem, 69(5), 940-945. https://www.redalyc.org/pdf/2670/267047824018.pdf. http://dx.doi.org/10.1590/0034-7167-2015-0116 
Haguette, T. M. F. (2013). Metodologias qualitativas na Sociologia. (14a ed.), Vozes.

Malta, D. C., Reis, A. A. C., Jaime, P. C., Neto, O. L. M., Silva, M. M. A., \& Akerman, M. (2018). O SUS e a Política Nacional de Promoção da Saúde: perspectiva resultados, avanços e desafios em tempos de crise. Ciência \& Saúde Coletiva, 23(1), 1799-1809. http://www.scielo.br/pdf/csc/v23n6/1413-8123csc-23-06-1799.pdf. 10.1590/1413-81232018236.04782018

Minayo, M. C. S. (2014). O desafio do conhecimento: pesquisa qualitativa em saúde (14a ed.), Editora Hucitec.

Ministério da Saúde. (2016). Câncer infanto-juvenil. INCA.2016. https://www.inca.gov.br/tipos-de-cancer/cancer-infantojuvenil.

Ministério da Saúde. (2020). Estimativas do Câncer Infantojuvenil. INCA. https://www.inca.gov.br/estimativa/cancer-infantojuvenil.

Patias, N. D., \& Von Hohendorff, J. (2019). Critérios de qualidade para artigos de pesquisa qualitativa. Psicologia em estudo, 24(1), 1- 14. https://www.scielo.br/scielo.php?pid=S1413-73722019000100236\&script=sci_arttext\&tlng=pt. https://doi.org/10.4025/psicolestud.v24i0.43536

Pettres, A. A., \& Da Ros, M. A. (2018). A determinação social da saúde e a promoção da saúde. Arquivos Catarinenses de Medicina, 47(3), 183-196. http://www.acm.org.br/acm/seer/index.php/arquivos/article/view/375/282.

Pontes, H. P., Praxedes, A. E. N. Q., Oliveira, M. G. P., Pinheiro, B. L. A., Rolim, K. M. C., \& Frota, M. A. (2018). Sentimentos vivenciados durante o tratamento do câncer infantil. CIAIQ2018, 2(1), 1167-1174. https://www.proceedings.ciaiq.org/index.php/ciaiq2018/article/view/1892/1842.

Oliveira, L. E., Júnior, C. A. J. S., Martins, R. S., Moura, A. A. A., Nascimento, C. L., Novais, T. A. M., \& Paranhos, S. B. (2018). Atividades Lúdicas desenvolvidas pela enfermagem em um hospital materno infantil. Revista Ciência em Extensão, 14(3), 159-69. https://ojs.unesp.br/index.php/revista_proex/article/view/1659/208.

Reis, N. S. P., Santos, M. F. G., Almeida, I. S., Gomes, H. F., Leite, D. C., \& Peres, E. M. (2018). A hospitalização do adolescente na ótica dos profissionais de enfermagem. Enferm. foco (Brasília), 9(2), 7-12. http://revista.cofen.gov.br/index.php/enfermagem/article/view/1057/435.

Rodrigues, B., Schimitt, G. M., Cozer, A. M., Feitosa, D. H. V., Neto, E. K. P., Rosa, I. M., Amâncio, L. C., \& Fernandez, F. C. (2019). Personificação da figura do palhaço para a promoção da saúde humanizada no projeto doutores da gargalhada. Brazilian Journal of Development, 5(8), 12335- 41. https://www.brazilianjournals.com/index.php/BRJD/article/view/2814.

Rodrigues, D. F. (2019). A música como instrumento de humanização na saúde da mulher. Faculdade Federal de Uberlândia, Uberlândia-MG. http://repositorio.ufu.br/handle/123456789/27684.

Silva, G. H., \& Piovesan, J. C. (2018). Juliane Claudia. Música no ambiente hospitalar: uma possibilidade de proporcionar alegria e ludicidade na internação. Vivências [Internet], 17(26), 204-19. http://www2.reitoria.uri.br/ vivencias/Numero_026/artigos/pdf/Artigo_17.pdf.

Silva, L. A. G. P., Baran, F. D. P., \& Mercês, N. N. A. (2016). A música no cuidado às crianças e adolescentes com câncer: revisão integrativa. Texto \& Contexto-Enfermagem, 25(4): https://www.scielo.br/scielo.php?pid=S0104-07072016000400308\&script=sci_arttext\&tlng=pt. https://doi.org/10.1590/010407072016001720015

Sousa, W. N. R. (2019). Sentimentos atribuídos pelas crianças e adolescentes acerca do processo da hospitalização. UFCG, Campina Grande - PB. http://dspace.sti.ufcg.edu.br:8080/jspui/handle/riufcg/11773.

Souza, J. B., Martins, E. L., Xirello, T., Urio, A., Barbosa, S. S. P., \& Pitilin, E. B. (2020). Interface entre a música e a promoção da saúde da mulher. Revista Brasileira em Promoção da Saúde, 33, 1 -10. https://periodicos.unifor.br/RBPS/article/view/9466. https://doi.org/10.5020/18061230.2019.9466

Utzumi, F. C., Lacerda, M. R., Bernardino, E., Gomes, I. M., Aued, G. K., \& Sousa, S. M. (2018). Continuidade do cuidado e o interacionismo simbólico: um entendimento possível. Texto \& contexto enferm, 27(2), 1 - 8. http://dx.doi.org/10.1590/0104-070720180004250016. 10.1590/0104-070720180004250016

Who. (1986). Primeira Conferência Internacional Sobre Promoção da Saúde. http://bvsms.saude.gov.br/bvs/publicacoes/carta_ottawa.pdf. 